\title{
Structured professional development for academic developers: A collaborative approach
}

\author{
Fiona O'Riordan \\ Dublin City University \\ Íde O'Sullivan \\ University of Limerick \\ Mary Fitzpatrick \\ University of Limerick
}

See next page for additional authors

Follow this and additional works at: https://arrow.tudublin.ie/ltcart

Part of the Scholarship of Teaching and Learning Commons, Teacher Education and Professional Development Commons, and the University Extension Commons

\section{Recommended Citation}

Fiona O'Riordan, Íde O'Sullivan, Mary Fitzpatrick, Margaret Keane, Claire McAvinia \& Angelica Risquez (2020) Structured professional development for academic developers: A collaborative approach, Innovations in Education and Teaching International, DOI: 10.1080/14703297.2020.1813189

This Article is brought to you for free and open access by the Learning Teaching \& Assessment at ARROW@TU Dublin. It has been accepted for inclusion in Articles by an authorized administrator of ARROW@TU Dublin. For more information, please contact arrow.admin@tudublin.ie, aisling.coyne@tudublin.ie, gerard.connolly@tudublin.ie.

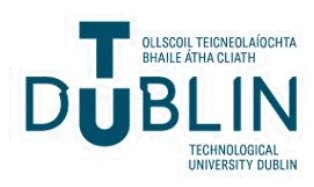


Authors

Fiona O'Riordan, Íde O'Sullivan, Mary Fitzpatrick, Margaret Keane, Claire McAvinia, and Angelica Risquez

This article is available at ARROW@TU Dublin: https://arrow.tudublin.ie/ltcart/82 


\section{Structured professional development for academic developers: A collaborative approach}

Fiona O'Riordan, Íde O'Sullivan, Mary Fitzpatrick, Margaret Keane, Claire McAvinia \& Angelica Risquez

To cite this article: Fiona O'Riordan, Íde O'Sullivan, Mary Fitzpatrick, Margaret Keane, Claire McAvinia \& Angelica Risquez (2020): Structured professional development for academic developers: A collaborative approach, Innovations in Education and Teaching International, DOI: 10.1080/14703297.2020.1813189

To link to this article: https://doi.org/10.1080/14703297.2020.1813189

曲 Published online: 28 Aug 2020.

Submit your article to this journal $\longleftarrow$

Џ Article views: 157

Q View related articles $\longleftarrow$

View Crossmark data $־$ 


\title{
Structured professional development for academic developers: A collaborative approach
}

\author{
Fiona O'Riordan (D) ${ }^{\mathrm{a}}$, Íde O'Sullivan ${ }^{\mathrm{b}}$, Mary Fitzpatrick ${ }^{\mathrm{b}}$, Margaret Keane ${ }^{\mathrm{c}}$, \\ Claire McAvinia ${ }^{d}$ and Angelica Risquez ${ }^{b}$
}

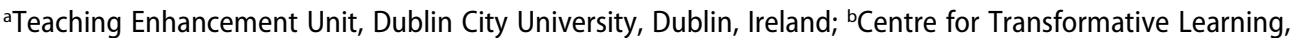
University of Limerick, Limerick, Ireland; 'Centre for Teaching and Learning, Maynooth University, Maynooth, Ireland; 'Learning, Teaching and Technology Centre, Technological University Dublin, Dublin, Ireland

\begin{abstract}
This paper shares the experience of a group of academic developers' engagement in collaboratively working towards the completion of an online open-access professional development (PD) course designed to support higher education teachers to engage with a new professional development framework. Committee members of the Educational Developers in Ireland Network set out to complete the course as a demonstration of their commitment to their own PD and to experience the process with a view to becoming facilitators of the course. An auto-ethnographic approach was used to capture this experience, and findings demonstrate an inspiring alternative to PD that supports academic developers in the quest to legitimise and prioritise their own PD in the context of highly pressurised roles.
\end{abstract}

\section{KEYWORDS}

Academic development; teaching and learning; professional development; collaboration; digital badges; open courses

\section{Introduction and background}

It has been argued that academic development has struggled to find its academic niche and a sense of 'tribal' identity (Bath \& Smith, 2004), and isolation and alienation are often reported by academic developers (O'Farrell \& Fitzmaurice, 2013). In addition, Blackmore and Blackwell (2006) highlight the increasing pressure to professionalise academic and, consequently, academic developer roles and argue for the development of both in parallel. More recently, the emergence of professional standards internationally is bringing into sharp focus academic developers' own professional development and everincreasing 'pressures to professionalise' (Blackmore \& Blackwell, 2006, p. 373). This implies that, while the focus for academic developers is usually placed on supporting the PD of teaching staff within their institutions, there is also an impetus for them to rethink their own PD. Therefore, finding opportunities for professional dialogue is important (Asghar \& Pilkington, 2018; Donnelly, 2015), and moving away from individual approaches to PD can promote transformative practice more effectively (Wenger, 1998). This can be facilitated through a community of practice approach to PD, underpinned by a social theory of

CONTACT Íde O'Sullivan Ide.Osullivan@ul.ie Centre for Transformative Learning, University of Limerick, Limerick V94 T9PX, Ireland

This article has been republished with minor changes. These changes do not impact the academic content of the article. (c) 2020 Informa UK Limited, trading as Taylor \& Francis Group 
learning (Kennedy, 2005). Such an approach can enhance interactions between colleagues within departments, different disciplines, across institutions, and between all those who teach (King, 2019).

From this perspective, this paper reports the experiences of a group of Educational Development in Ireland Network (EDIN) members who completed an online open-access course collaboratively to reflect on and advance their own PD. As academic developers, members of EDIN have an important part to play in rolling out a new national PD Framework $^{1}$ which has been proposed in Ireland by the National Forum for the Enhancement of Teaching and Learning. The Framework aims to empower those teaching in higher education to engage in meaningful personal reflection and peer dialogue around their PD (Donnelly \& Maguire, 2018, p. 6). Its implementation is being assisted through online open-access PD courses, the first of which is PACT - Making a Commitment to Professional Development (National Forum for the Enhancement of Teaching and Learning, 2019). ${ }^{2}$ This course offers a cyclical, scholarly, approach to PD through reflective practice, where being assisted and mentored in the reflection process is a key transformative factor (Donnelly \& Maguire, 2018). As educational developers are expected to support and encourage colleagues who teach within their institutions to engage with PACT and the new Framework, EDIN members prioritised completion of the course themselves. It was important to lead by example in terms of PD, and to experience the process of taking the course with a view to facilitating it for the wider EDIN community of academic developers and academics within members' institutions. A self-selecting sextet of academic developers, who were geographically distant from each other and working in different contexts within higher education (university, private college, institute of technology), was formed. They jointly agreed to work in collaboration towards the completion of the four elements of the PACT course:

- Element 1: 'Am I ready for PD?' involved reflecting on what is involved in making a commitment to PD and preparing for it.

- Element 2: 'Planning for my PD' explored the national PD framework.

- Element 3.1: 'Taking action for my PD' involved the design of a personal PD action plan.

- Element 3.2: 'Taking action for my PD' introduced peer critical discussion of action plans and final reflections.

The PACT material is designed to be completed on an individual basis, but it was felt that a collaborative approach to the completion of the elements would work best in order to facilitate interaction and learning across the different institutions, as advocated by King (2019). At the outset of this collaborative process, key monthly deadlines were agreed for (i) submission of individual work as guided by each of the course elements; (ii) peer review of each other's submissions; (iii) synchronous meetings. Each member of the group committed to share their course work with each other for peer review. This would be followed by another synchronous meeting to discuss progress, insights and learning points. It was initially decided to record meetings to accommodate colleagues unable to attend on a particular date. However, the recordings subsequently served as a dataset of shared experiences beyond the course itself and relating to the everyday work, challenges and PD of the participants, which could subsequently be analysed as outlined 
in this paper. A deadline of 1 month was set for completion of each course element with a four-month deadline to complete the course. Apart from these deadlines, no formal rules were established. This paper explores the motivations, outcomes, and implications of working collaboratively, towards a shared objective, in this manner.

\section{Methodology}

While not the original objective, it became apparent that the collaborative process of academic developers working towards a shared PD goal was, in itself, worthy of exploration. The initial purpose of meeting online was to discuss the completion of each course element and to prepare for the next element. However, conversations moved beyond participants' experience of completing the course and into other PD practices of academic developers. Given the richness of the dialogue in the first online meeting, it was evident that the discussion surrounding the process itself was a source of data that could inform future PD practices of busy academic developers struggling to prioritise and find time for their own PD. Consequently, while continuing to pursue the goal of completing the course, the group agreed to explore the process itself in which they became researchers as well as active research participants. Formal ethical approval was sought from one of the researcher's institutional research ethics committee. The Chair of the Committee advised that formal committee approval was not required for this form of research, where the researchers are those being researched and are incorporating their own personal reflections in the data. Nonetheless, all procedures including the collection, storage and processing of data were in line with the institution's guidance on research ethics, which is aligned with international best practice (BERA, 2018).

The protocol for moving forward ethically was agreed among the researchers. All six members of the group provided informed verbal consent, recorded at the end of the first online meeting, to allow the recordings and the reflective texts to be used for research purposes. To ensure confidentiality, it was agreed that any material used from the dataset would be anonymised to protect the identity of individual participants and the original datasets would be destroyed after analysis.

The study adopted an auto-ethnographic approach involving the analysis of the recordings of the four meetings, along with the analysis of participants' post-course written reflections. This approach allowed participants to understand the process involved and reveal the culture in which they operated. Rooted in auto-ethnography is the desire to describe personal experiences in meaningful and accessible ways in order to gain a greater understanding of cultural experience while sensitising readers to issues of identity and experience (Ellis et al., 2011). Indeed, a central driving force in autoethnography is the question of 'who reads our work, how are they affected by it, and how does it keep a conversation going?' (Ellis et al., 2011, p. 284). The approach taken was inductive in nature. In the sharing of experiences, it became clear that the process participants engaged in would lead to a product, namely, insight into a culture with which academic developers could identify, and stimulation of a conversation to which they could contribute. Consequently, the shared experiences of the sextet could be beneficial in developing a richer understanding for those within and outside their community. In essence, the dataset consisted of reflective ethnographies, which primarily captured insights into how participants changed as a result of engaging in this form of PD 
as well as co-constructed narratives, which reveal much about how participants coped with challenges facing them in terms of their own PD.

The participants' credibility and sharing of authentic and honest reflections on experience throughout the process, knowing that the story will be of benefit to others in their community, validate this form of research. This was further authenticated in discussions following the presentation of initial findings at the 2018 Staff and Educational Development Association (SEDA) conference. It is important to acknowledge a limitation of the data as not arising from purposefully designed research instruments. The primary purpose of the online meetings and recordings was to share experiences for course completion and secondary to that purpose was the analysis for research. However, the data collected served to directly capture authentic discussion of participant experience, consequently addressing the posed problem of capturing indirect accounts of experiences via other research instruments such as questionnaires (Cotton et al., 2010) and also overcoming the issue of memory sometimes associated with an auto-ethnographic approach (Clandinin \& Connelly, 2000). The recorded discussions thus capture the 'richness, nuance and complexity' (Clandinin \& Connelly, 2000, p. 83) of the issues at hand.

Following the example of recorded diaries in Jefferies and Hyde (2009), it was decided to analyse meeting recordings as qualitative data using the thematic approach of Braun and Clarke (2006). Each recording was reviewed using Braun and Clarke's six stages to generate codes and themes, and the analysis was reviewed by the group. Given their role as participants and insider researchers, group members were cognisant of emphasis on personal reflection (Clandinin \& Connelly, 2000) and the concept of reflexivity as defined by Scott and Morrison (2007, p. 203) as 'the process by which the researcher comes to understand how they are positioned in relation to the knowledge they are producing'. They were equally mindful that reflexivity is a characteristic of research 'where the [research] subject and object are not clearly separated'. In an effort to manage this, each recording was coded and themed and then verified by another member of the group. Additionally, each participant's post-course written reflections on the process were coded using NVivo software and verified by another member of the group. Findings of this qualitative analysis are outlined next.

\section{Analysis}

Five main themes emerged during the analysis of data based on frequency of codes. The first theme explores the process of collaborative PD, followed by the second, which discusses commitment to one's own PD. The challenge of protecting time and space for this commitment is discussed as the third theme, and leads into the fourth, relating to supporting institutional PD. The section concludes with discussion on the final theme of professional networking, such as the one experienced in this process, promoting deep and meaningful engagement in professional development, as was the aim of engaging in such PD courses (Donnelly \& Maguire, 2018).

\section{The process of collaborative PD}

The most valuable, and commonly cited, benefit to the participants was the collaborative approach taken: 'collaboration was the engine that drove PD for me' (Participant D); 'the 
collaborative process in PACT gave me the opportunity to work closely with highly valued, kind and trusted critical friends from EDIN' (Participant D). Participants stressed that they would have struggled to complete the course 'alone without the support of others' (Participant F). This commitment to collaboration was evidenced through a sense of responsibility and accountability to the group: 'I respected my colleagues' time and effort and did not want to let them down with regard to completing work on time' (Participant A); 'I work more efficiently if I have to adhere to a deadline, especially if I am accountable to colleagues too!' (Participant E). This overall commitment to the peer group resulted in increased motivation to engage with their own PD. There was a sense that this collaborative approach allowed the group, as academic developers, to explore and interpret requirements as they journeyed through the process together and '... the conversations with critical friends were an inherent part of the process' (Participant $\mathrm{C}$ ).

Collaboration facilitated more honest reflections and dialogue; 'I gain inspiration and energy from connecting to others' (Participant C); '[L]earning from each other's reflections and submissions was very helpful and was an unexpected outcome that contributed a lot to my PD' (Participant A); and '[T] he dialogue was extremely valuable for many reasons ...' (Participant B). This is redolent of Asghar and Pilkington (2018, p. 136) observation that professional dialogue supports ' ... enhanced self-reflection and meaning-making and the development of a new under-standing about practice, implying professional maturity'.

Despite the perceived benefits of collaborating, participants admitted that sharing one's reflections can be 'terrifying', reinforcing the importance of nurturing trust in the collaborative process. What helped reassure participants in this regard was that the leader of the group led the way each month, uploading her own elements of the course first, putting her reflections online for others to follow.

\section{Commitment to one's own PD}

Professionalising academic development, as advocated by Blackmore and Blackwell (2006), requires commitment to academic developers' own PD. The collaborative process compelled participants to do this; 'from the first conversation it was clear that we had created a welcoming and safe space ... where accountability would drive us to complete not only the badge but to solidify our commitment to our own PD' (Participant C).

Engaging in the process focussed commitment to PD; be it their own, or supporting the PD of others. It transpired that all participants, while clearly committed to progressing the PD of others in the academic community, were often doing so to the detriment of their own. This realisation was insightful and caused participants to recommit to their own PD. Pledging commitment to one's own PD appeared to be a challenge for all, evidenced in the honest and open discussion; 'The space that we had created to discuss our PD validated and legitimised the need to prioritise this aspect of our roles and to make a firm commitment to our PD' (Participant C).

The post-course reflection data indicated that there is a sense that participants need permission to engage in their own PD; 'The collaborative practice supported me prioritising my commitment to PD and reflection on my practice. It was almost as if working collaboratively gave me the "excuse" I needed to protect the time required" (Participant A). Another participant reflected on her commitment being ' ... meeting the deadlines for peer meetings' (Participant B) rather than prioritising her own PD. Given the nature of 
these personal reflections, it was agreed that trust amongst members of a collaborative group was important; 'On a deeper level, I was inspired by the honest contributions of my colleagues on the team. It was clear that this was a group of passionate reflective academic developers who were committed to PD as a tool to enhance their work' (Participant A).

Notwithstanding the trust element of critical friends reviewing each other's work, the peer review element facilitated important feedback and sharing of tips and advice in an open manner; 'We all put ourselves in a space for open and frank discussion where vulnerabilities and strengths were equally outlined' (Participant B). The group were supportive of one another and motivated each other to maintain momentum.

\section{The challenge of protecting time and space for PD}

Related to commitment to one's own PD is the challenge of finding the time and space to do so. Engagement in this PACT course calls for time and space to be awarded to the process (Donnelly \& Maguire, 2018), although the initial motivation for the group to engage with the course was to be able to facilitate others to take it. This points to the fact that they took this opportunity primarily to support the PD of others rather than to value and engage in their own PD as an important aspect of their own roles; 'We sometimes view it as separate to our roles and as something we are doing simply for ourselves' (Participant F). Prioritising PD, and creating the space to do it, had previously been viewed as difficult or impossible for participants. Longer term, participants expected to find it easier to protect this time having experienced the value of PD themselves. Participants spoke about how making space for reflection as part of taking the course was viewed as development, and this speaks to the value of professional dialogue (Asghar \& Pilkington, 2018). Participants were also keen to maintain the momentum of reflective practice, for example, protecting time to read more and reflect upon actions. A number of participants spoke about setting up an e-portfolio or a blog to create a space to gather their reflections. Further collaboration on this type of PD activity may help in making this commitment to PD. There was a sense of having permission to commit to PD through taking the course but also through the collaborative nature of the activity; 'It is appropriate to block and protect time for it. I feel more confident about doing that with others around the country doing it' (Participant D).

\section{Supporting institutional PD}

Related to the challenge of finding time, and prioritising PD, all agreed that in order to continue supporting other colleagues within their respective institutions, and to lead by example, protected time and space should be carved out for academic PD. Institutional recognition of PD was considered important and speaks to notions of PD having impact, sustainability, and demonstrable value to an institution (Bamber, 2013). Although participants were geographically distant from each other, working in three different contexts within Higher Education, they recognised the variation of experiences across these contexts, and similar challenges were evidenced in the data: 'We uncovered a number of common issues related to our roles but also related to how we perform in role' (Participant D). 
Where institutions recognise and value PD, it appeared to be easier to prioritise it. Whilst engagement in the course as a collaborative endeavour helped prioritise PD as a consequence of deadlines and meetings set by the group, this was tempered by other strategic priorities and developments that required more immediate attention. Thus, commitment to PD involves strategic decisions that feed into current priorities and commitments. This is reflective of best practice as Sugrue et al. (2018, p. 2343), who conducted a systematic review of academic development work, suggest where PD initiatives are ' ... harnessed in a more strategic manner' they offer greater visibility and prominence.

On an individual basis, in three instances the course and collaborative process came along at a timely moment when participants were stocktaking in some way - reexamining their role and priorities, taking up a new role, or identifying areas of activity for the future. This PD experience afforded the participants an impetus for them to interpret their own professional roles beyond the course, for example: 'I have changed how I approach my work on a day to day basis as a result of having those goals, am reconsidering my role and where I need to be and go next' (Participant F).

\section{Professional networking and deep engagement with PD}

Working as a group gave the participants the means to explore the new national framework together in the context of their own PD and supporting academic PD; 'Having undertaken the course in a collaborative group, I feel I am now in a much stronger position not only to truly understand the various elements of the framework in the context of myself and others but also to fully understand where I am currently and where I need to go in respect of my own PD' (Participant F). This allowed the individuals to reflect on their roles in relation to it. Analysis of the recorded meetings showed that, by virtue of their roles, the participants are actively engaged in reflective type activities required in PD processes. Consequently, they would need to ensure that they facilitate this skill when they are delivering PD initiatives, such as the PACT online course, with those who teach within their respective institutions. They felt it was important to align their own PD with appropriate PD frameworks to show how this could be done, and model the process to others teaching in higher education.

\section{Discussion}

This paper has described the PD experience of a group of academic developers that helped them to legitimise and prioritise their own PD in the context of increasingly pressurised working environments. This is in line with King's (2019) expectation that PD for all elements of the academic role should be an integral part of professional life. While the initial discussions relate to the challenges and benefits of collaboratively embarking on a formal professional development course, the data evidences the experiences of working collaboratively on professional development more generally. The findings have implications for other professional development activities and highlight the potential role of collaborative professional development in the continuing professional development of an academic. 
The participants in this experience welcomed it as an additional source of trust and motivation within the academic development community (Bath \& Smith, 2004), although they did acknowledge the prospect of sharing was 'terrifying', highlighting the importance of nurturing a safe and trusting 'tribe' of collaborators.

Narrative reflection proved to be an effective PD tool for self-support and to counteract the usual feeling of isolation and alienation of the academic developer (O'Farrell \& Fitzmaurice, 2013). By analysing their sense of self as an academic developer, participants enhanced 'collegiality and sustainable peer support in networks' (p. 235). The sense of mutual dependency and accountability reported confirms participants' cognisance of the existence of the community as central to their internalisation of learning, which is consistent with the community of practice approach to PD, underpinned by a social theory of learning (Kennedy, 2005).

The participants recognised that progress with their personal reflection was greatly enabled within the group because of their interactions and their awareness of the formation of a community, and not merely because of planned learning episodes. Negotiating a joint enterprise gave rise to relations of mutual accountability among those involved, arguably promoting greater capacity for transformative practice than an individual approach to PD would allow (Wenger, 1998). This was coherent with the cyclical, scholarly approach to PD through reflective practice, advocated by Donnelly and Maguire (2018), where being assisted and mentored in the reflection process, through the online course and by colleagues, is a key transformative factor.

What was crucial to this process was that power was negotiated in such a way that it allowed for the expression of the affective dimension of the participants' roles in a safe environment (O'Farrell \& Fitzmaurice, 2013). In this vein, Kennedy (2005) reminds us that the issue of power is fundamental to successful PD within a community of practice and warns against the potential for communities of practice to perpetuate dominant discourses in an uncritical manner. She goes on to categorise the community of practice PD approach as an intermediate step towards more transformative options that afford an increasing capacity for professional autonomy.

The participants in this PD initiative engaged in an auto-ethnographic approach to involve themselves in professional reflection, validate each other as producers of knowledge, and recognise their role in PD and decision-making. Engaging collaboratively in this form of reflective practice was a means to claim their academic discipline and contributed to the formation of their identity as a community of scholars (Bath \& Smith, 2004). Under these conditions, this approach to the completion of an online PD course provided an 'antidote to the constricting nature of the standards, accountability and performance management agenda' (Kennedy, 2005, p. 247). Spowart et al. (2019), in speaking of the opportunities to enhance professional development provision through the implementation of professional recognition schemes, highlight the importance of 'engagement from critical 'others" (p. 1309) to ensure the developmental potential of such recognition schemes. While the National Professional Development Framework is not a recognition scheme, the experience of academic developers working towards the completion of PD activities which are closely aligned to the Framework reinforces the benefits and importance of collaborative professional development provision in the implementation of professional recognition schemes. 


\section{Conclusions and recommendations}

This paper presented an example of how one group of academic developers is responding to changes in teaching and learning in higher education in relation to the introduction of a new national PD Framework. It reported on the collaborative engagement of the group with an open access online PD course based on such framework, as a positive alternative to individual PD. The approach enabled a PD process that overcame a range of recognised practical challenges. The experience was highly rewarding and provided participants with the opportunity to reflect critically on the nature of PD, their own PD, and lessons learned, in order to frame and guide the PD of their academic colleagues. The auto-ethnographic approach to this work was found to be valuable, and the qualitative dataset yielded some rich insights to inform future practice.

In light of the positive PD experiences reported and analysed herein, a number of recommendations for other academic developers embarking on similar processes in support of their own PD are proposed. A structured, collaborative approach to PD for academic developers, working in challenging and highly pressured environments, is suggested. Equally, it is recommended that such a collaborative process should incorporate narrative reflection that will allow for later evaluation and meta-reflection, valuable in planning for the academic PD activities of colleagues. This kind of PD process should be a joint, negotiated, one that nurtures a safe and trusted space for those involved. This, alongside the huge value gained from the process, indicates the essential importance of collaborative PD for academic developers in increasingly busy working contexts.

\section{Notes}

1. https://www.teachingandlearning.ie/publication/national-professional-developmentframework-for-all-staff-who-teach-in-higher-education/

2. https://opencourses.teachingandlearning.ie/open_course/getting-started-with-professionaldevelopment-pact/

\section{Disclosure statement}

No potential conflict of interest was reported by the authors.

\section{Notes on contributors}

Fiona O'Riordan is an Academic Developer in the Teaching Enhancement Unit at Dublin City University (DCU) supporting academics' research and developing evidence-based pedagogy. She also facilitates academic development workshops and accredited professional development modules.

Íde O'Sullivan is a Senior Educational Developer in the Centre for Transformative Learning at the University of Limerick, where she is Curriculum Development Support Lead and is Course Director of the Graduate Diploma/MA in Teaching, Learning and Scholarship.

Mary Fitzpatrick is Head of the Centre for Transformative Learning at the University of Limerick. Her key area of expertise is the professional development of teaching and learning through working with, and supporting, faculty through key initiatives which promote academic development and teaching excellence. 
Margaret Keane is a Teaching and Learning Development Officer in the Centre for Teaching and Learning at Maynooth University. She is Programme Co-ordinator of the Postgraduate Certificate and Diploma in Higher Education Teaching, Learning and Assessment.

Claire McAvinia is a Learning Development Officer at the Learning, Teaching and Technology Centre, TU Dublin. She teaches on the LTTC's Postgraduate Certificate and Diploma in University Learning and Teaching, and MSc Education.

Angelica Risquez is a Lead Educational Developer at the Centre for Transformative Learning at the University of Limerick. She teaches and advocates technology-enhanced learning at institutional, national and international level.

\section{ORCID}

Fiona O'Riordan (ID) http://orcid.org/0000-0002-0139-5169

\section{References}

Asghar, M., \& Pilkington, R. (2018). The relational value of professional dialogue for academics pursuing HEA fellowship. International Journal for Academic Development, 23(2), 135-146. https:// doi.org/10.1080/1360144X.2017.1386566

Bamber, V. (2013). Evidencing the value of educational development. SEDA Special 34.

Bath, D., \& Smith, C. (2004). Academic developers: An academic tribe claiming their territory in higher education. International Journal for Academic Development, 9(1), 9-27. https://doi.org/10. 1080/1360144042000296035

Blackmore, P., \& Blackwell, R. (2006). Strategic leadership in academic development. Studies in Higher Education, 31(3), 373-387. https://doi.org/10.1080/03075070600680893

Braun, V., \& Clarke, V. (2006). Using thematic analysis in psychology. Qualitative Research in Psychology, 3(2), 77-101. https://doi.org/10.1191/1478088706qp063oa

British Educational Research Association [BERA]. (2018). Ethical guidelines for educational research (4th ed.). British Educational Research Association. https://www.bera.ac.uk/publication/ethicalguidelines-for-educational-research-2018

Clandinin, D. J., \& Connelly, M. F. (2000). Narrative inquiry: Experience and story in qualitative research. Jossey-Bass Publishers.

Cotton, D. R. E., Stokes, A., \& Cotton, P. A. (2010). Using observational methods to research the student experience. Journal of Geography in Higher Education, 34(3), 463-473. https://doi.org/10. 1080/03098265.2010.501541

Donnelly, R. (2015). Values informing professional practice in academic professional development. Infonomics Society, 4(1), 540-547. https://doi.org/10.20533/ijtie.2047.0533.2015.0071

Jefferies, A., \& Hyde, R. (2009). Listening to the learners' voice in HE: How do students reflect on their use of technology for learning? Electronic Journal of e-Learning, 7(2), 119-126.

Kennedy, A. (2005). Models of continuing professional development: A framework for analysis. Journal of In-Service Education, 31(2), 235-250. https://doi.org/10.1080/13674580500200277

King, H. (2019). Continuing professional development: What do award-winning academics do? Educational Developments, 20(2), 1-5.

National Forum for the Enhancement of Teaching and Learning. (2019). Getting started with professional development - PACT. https://opencourses.teachingandlearning.ie/open_course/gettingstarted-with-professional-development-pact/

O'Farrell, C., \& Fitzmaurice, M. (2013). Academic developers using narrative to support our professional development. Innovations in Education and Teaching International, 50(3), 227-237. https:// doi.org/10.1080/14703297.2012.760776

Scott, D., \& Morrison, M. (2007). Key ideas in educational research. Continuum. 
Sugrue, C., Englund, T., Solbrekke, T.D., Fossland, T. (2018). Trends in the practices of academic developers: trajectories of higher education?. Studies in Higher Education 43(12), 2336-2353. https://doi.org/10.1080/03075079.2017.1326026

Spowart, L., Winter, J., Turner, R., Burden, P., Botham, K., Muneer, R., van der Sluis, H., \& Huet, I. (2019). 'Left with a title but nothing else': The challenges of embedding professional recognition schemes for teachers within higher education institutions. Higher Education Research and Development, 38(6), 1299-1312. https://doi.org/10.1080/07294360.2019.1616675

Wenger, E. (1998). Communities of practice: Learning, meaning and identity. Cambridge University Press. 